\title{
ARTIGO
}

\section{Assédio moral institucionalizado: trajetória de operadores de teleatendimento com LER/DORT}

Institutionalized moral harassment:

trajectory of telemarketing operators with RSI/WRMD

Asedio moral institucionalizado:

trayectoria de operadores de telemarketing con LER/DORT

Adryanna Cardim de Almeida'

Paulo Gilvanne Lopes Pena ${ }^{2}$

Maria do Carmo Soares de Freitas ${ }^{3}$

Mônica Angelim Gomes de Lima ${ }^{4}$

RESUMO: O presente artigo buscou compreender como funciona o assédio moral sobre os trabalhadores e principalmente o que ocorre quando eles adoecem por lesões por esforços repetitivos/distúrbios osteomusculares relacionados ao trabalho -

\footnotetext{
1 Doutoranda em Saúde Pública, Instituto de Saúde Coletiva (UFBA), E-mail: adryanna@terra.com.br

2 Doutor em Sócio-Economia do Desenvolvimento. École des Hautes Études en Sciences Sociales, EHESS, França; Professor Titular da Faculdade de Medicina da UFBA.

3 Doutora em Saúde Coletiva (UFBA), Pós-doutorado em Saúde Pública pela Escola Nacional de Saúde Pública - ENSP-RJ; Professora do Mestrado em Saúde, Ambiente e Trabalho (UFBA).

4 Doutora em Saúde Coletiva (UFBA), Pós-doutorado sobre Prevenção da Incapacidade Prolongada (Work Disability Prevention), na University of Toronto, Canadá; Professora da Faculdade de Medicina da UFBA.
} 
LER/DORT. Para este estudo qualitativo foram entrevistados vinte e oito operadores com LER/DORT, entre 2005 e 2008, e feitas observações nos ambientes de trabalho de dez empresas. No âmbito do teleatendimento, o assédio moral ocorre dentro da organização através de supervisores, coordenadores e médicos do trabalho. Causam perplexidade os abusos e humilhações contra os trabalhadores que procuram locais de amparo, defrontando-se com a falta de acolhimento. Observam-se inúmeras consequências causadas por essas situações de violência, do constrangimento até situações extremas de risco de suicídio. Faz-se necessário construir medidas que contemplem ações preventivas e explorar as relações com os colegas de trabalho, a construção de resistências e a percepção da injustiça.

Palavras-Chave: trabalho; assédio moral; sofrimento psíquico; lesões por esforços repetitivos; telemarketing; saúde do trabalhador.

ABSTRACT: This article tried to understand how psychological harassment on workers happen and especially what happens when they fall sick with Repetitive Strain Injury/ work-related musculoskeletal disorders - RSI/WRMD. Twenty-eight operators with RSI/WRMD were interviewed between 2005 and 2008 and observations in the workplace of ten companies were made for this qualitative study. In the range of telemarketing, psychological harassment happens within the organizations by supervisors, coordinators and occupational doctors. Countless consequences of these situations of violence are observed: embarrassment and even extreme situations of suicide risk. It is necessary to create measures that include preventive actions. The continuity of studies should explore fields such as relationships with co-workers, the creation of resistances, and the perception of injustices.

Keywords: workplace; psychological harassment; psychic suffering; repetitive strain injury; telemarketing; occupational health.

Laborare. Ano I, Número 1, Julho/2018, pp. 63-84. ISSN 0000-0000. http://trabalhodigno.org/laborare 


\section{INTRODUÇÃO}

O teleatendimento é um fenômeno contemporâneo responsável por mudanças nos processos de tecnologias e na questão da aceleração do tempo. É resultado de um momento da sociedade capitalista e que também traz implicações não completamente exploradas para o mundo do trabalho e para a saúde desses trabalhadores.

O desenvolvimento acelerado na indústria do telemercado ocorre tanto em países desenvolvidos quanto em países em desenvolvimento e relaciona-se com a pósindustrialização, refletindo o predomínio econômico do ramo de serviços, o qual sustenta a economia de produção de massa (Norman, Tornqvist e Toomingas, 2008; Braga, 2006).

Essas empresas contam com métodos rigorosos de controle interno que podem ser executados através das monitorias de qualidade, realizadas via escutas telefônicas dos atendimentos dos operadores em tempo real e gravações dessas ligações para posterior avaliação. Um processo de trabalho com características marcadamente tayloristas (Braga, 2006; Thirión,2007; Rosenfield, 2007).

Pena, Cardim e Araújo (2011) apontaram para a existência de um "taylorismo cibernético" em que o uso da inteligência artificial, introduzida pelos sistemas informatizados de rede, utiliza-se de softwares concebidos com matrizes dos princípios tayloristas, resultando em um conjunto de patologias que formam o complexo perfil epidemiológico nessa categoria.

Ritmos excessivos, múltiplas tarefas, variações grandes e imprevistas no trabalho, atividades monótonas e sem autonomia, tempo cronometrado, difícil relacion amento com clientes, podem constituir-se em fatores preponderantes para o desencadeamento de agravos à saúde mental desses teleoperadores, evidenciados 
nos afastamentos por transtornos mentais e de comportamento (Fernandes, 2002; Lucca e Campos, 2010; Ziliotto e Oliveira, 2014).

Os call centers apresentam novas formas de trabalho, todavia, utilizam-se de velhas práticas de controle, exigências, constrangimentos e humilhações (Silva, Oliveira e Souza, 2011). Quando os trabalhadores adoecem, as práticas discriminatórias e estigmatizantes são amplificadas. Adoecer e viver com LER/DORT tem implicações na relação com o trabalho, com os colegas e os supervisores. Nesse contexto, o assédio moral apresenta-se como mais uma ferramenta de gestão (Heloani, 2004). Uma ferramenta não legalmente aceita, no entanto, institucionalizada em suas práticas para gerir a organização.

O assédio moral é um tema complexo e, conceitualmente, ainda há imprecisões. (Cassitto et al., 2004; Guimarães e Rimoli, 2006). Para a Agência Europeia para a Segurança e a Saúde no Trabalho (2015, p. 1), o assédio moral "envolve, frequentemente, o uso indevido ou o abuso de poder, em situações em que as pessoas visadas têm dificuldade em se defender. Um comportamento injustificado e continuado para com um trabalhador ou grupo de trabalhadores, susceptível de constituir um risco para a saúde e segurança”.

$\mathrm{O}$ adoecimento em larga escala dos trabalhadores dessa área torna-se preocupante pela magnitude e por atingir uma importante população. Um aspecto ainda necessário a ser discutido é o significado atribuído ao adoecimento e às repercussões da interação indivíduo-contexto na produção intersubjetiva desses trabalhadores com LER/DORT. Alguns elementos devem ser elencados, conforme Vieira et al (2012, p.11), dentre eles que o assédio moral possui dimensões que suplantam o campo subjetivo e que algumas análises objetivam relacionar este fenômeno a um determinado "perfil psicológico" dos assediados e assediadores. Entretanto, devem-se "reconhecer as condições sociais de produção que os colocam nessas relações 
antagônicas e instrumentais". Nesta perspectiva, este estudo objetivou compreender como o assédio moral funciona na organização e principalmente quando esses trabalhadores adoecem por LER/DORT.

\section{MÉTODO}

Tratou-se de um estudo de abordagem etnográfica, realizado de 2005 a 2008, com operadores de telemarketing ou teleoperadores, com LER/DORT, da cidade de Salvador-BA. Contou com 28 (vinte e oito) informantes-chave e destes, foram selecionados 10 (dez), baseados nos seguintes critérios: trabalhar como operador de telemarketing; possuir diagnóstico clínico de LER/DORT; trabalhadores de ambos os sexos que estivessem demitidos ou na ativa e com benefício previdenciário. Todos os trabalhadores possuíam como última ocupação, a função de teleoperador.

Os locais de trabalho foram analisados como forma de conhecer e melhor elucidar os processos e ambientes de trabalho dos operadores. Foram realizadas dez visitas a call centres, sendo três em centrais com menos de 100 postos de trabalho; três, em centrais com 100 a 500 postos de trabalho e quatro em centrais com mais de 500 postos de trabalho.

A análise das narrativas dos sujeitos, a partir de suas entrevistas gravadas e transcritas foi complementada com os registros do diário de campo. Além disso, foi feita uma análise documental sobre condições de trabalho e saúde em centrais de teleatendimento relacionadas ao estudo. Foram analisados documentos técnicos emitidos por órgãos de vigilância e de fiscalização em saúde do trabalhador sobre a organização e processo de trabalho; documentos administrativos de empresas de teleatendimento, análises ergonômicas de trabalho, relação de atestados médicos contendo a classificação internacional de doenças (CID-10) e termos de ajustamento de conduta realizados pelo Ministério Público do Trabalho $5^{\text {a }}$ Região. 
Dessa abordagem nasceu uma análise complexa e necessária à compreensão sobre a enfermidade nesta categoria de trabalhadores. Das análises das narrativas, foi feita a seleção de significantes ou unidades analíticas, expressas nas falas desses trabalhadores, sujeitos do estudo. Para Geertz (1989) e Barthes (1997), os significantes, termos ou sentenças, expressam os aspectos mais significativos do problema.

Esta análise buscou evidenciar os significantes do mundo intersubjetivo e significantes dos sintomas, ressaltando os aspectos relacionados ao assédio moral e violências psicológicas a que são submetidos estes trabalhadores com lesões por esforços repetitivos.

O estudo seguiu procedimentos éticos, em conformidade com o estabelecido na Resolução do Conselho Nacional de Saúde nº196/96 para pesquisa em seres humanos, sendo registrado no Comitê de Ética em Pesquisa da Maternidade Climério de Oliveira sob o $n^{\circ}$ 002/08 e aprovado pelo Parecer/Resolução no 021/2008. Obteve ainda a aprovação da pesquisa junto ao sindicato da categoria e aos grupos de doentes lesionados que se organizam de forma independente. Os nomes dos informantes citados são fictícios para preservar suas identidades nos extratos de suas narrativas.

\section{RESULTADOS E DISCUSSÃO}

O assédio moral ganhou centralidade neste estudo em função das repetições presentes em narrativas dos operadores de telemarketing ou teleoperadores, depoimentos dos dirigentes sindicais e em reuniões da Comissão de Saúde do sindicato. Vários casos de constrangimentos, descompensações de natureza psicológica e psicossomáticas foram notificadas neste cotidiano de trabalho.

Laborare. Ano I, Número 1, Julho/2018, pp. 63-84. ISSN 0000-0000. http://trabalhodigno.org/laborare 
As categorias assédio moral e violência psicológica, que serão conceituadas adiante, foram agrupadas neste artigo não somente no local de trabalho, mas também em diferentes circunstâncias, sempre decorrentes do seu adoecimento. Estudo realizado pela Organização Internacional do Trabalho (OIT) nos países da União Europeia denunciou que as experiências de violência nos locais de trabalho já ultrapassam as fronteiras, os ambientes de trabalho e as categorias profissionais (OIT, 1998). Conforme o Terceiro Inquérito Europeu sobre Condições de Trabalho, realizado em 2000, um em cada dez trabalhadores reportaram serem vítimas de intimidação no local de trabalho (Cassitto et al., 2004).

Barreto (2004), analisando trabalhadores do ramo químico, farmacêutico, plástico e afins de São Paulo, estimou que $42 \%$ destes apresentavam histórias de humilhações e constrangimentos, demonstrando o impacto do assédio moral no país. As discussões em torno do assédio moral ganharam projeção no Brasil após o ano de 2000, na esfera da saúde mental e trabalho, em virtude do elevado número de afastamentos do trabalho por distúrbios psíquicos, principalmente depressão.

Os operadores de telemarketing vivenciam o assédio moral constantemente no trabalho. Quando são portadores de alguma doença relacionada ao trabalho, como as LER/DORT que têm alto poder incapacitante, estas experiências tornam-se exacerbadas. Constrangimentos ocasionados tanto pelos supervisores e coordenadores, como também por médicos do trabalho da empresa.

Por milhões de vezes eu ouvi [referindo-se ao supervisor]: 'tem milhões de pessoas que estão querendo seu lugar [enfatiza]'. Então isso amedrontava. Então, a gente tinha que correr para poder permanecer na empresa, até porque eu precisava do emprego. (Viviane) 
A expressão acima "por milhões de vezes" traduz a repetição de comportamentos inadequados ou exposição prolongada de situações constrangedoras no ambiente de trabalho. Verifica-se a hostilidade empregada pelo supervisor para fazer o trabalhador aumentar sua produtividade, com ameaças explícitas de desemprego, que o amedrontava, e lhe trazia um sentimento de inferioridade. Para Beswick et al. (2006), esse tipo de assédio moral está subsidiado pela organização do trabalho.

Maciel et al. (2007), analisando o Inventário Laymann de Psicoterrorismo no Trabalho (LIPT), observaram que um indivíduo é considerado vítima de assédio se tiver um sentimento de constrangimento frente a um ou mais comportamentos perpetrados por uma ou mais pessoas, por um determinado período. Examina-se que a situação relatada não se caracteriza como uma situação pontual e estanque. A organização do trabalho consente e estimula a prática da inferiorização dos operadores de telemarketing pela hierarquia, do mesmo modo que se utiliza de uma linguagem irônica como "deboche" como um instrumento de gestão.

O uso dessas práticas de assédio moral pelas hierarquias não resulta de iniciativas pessoais de gerentes, mas se inscreve no modelo taylorista de organização do trabalho praticado nas empresas de teleatendimento. Objetiva especificamente impor uma disciplina rigorosa por meio da humilhação para acelerar o trabalho e manter o tempo médio de atendimento (TMA) em elevada produtividade. Isso leva o trabalhador a agilizar as operações prescritas para diminuir o tempo de exposição ao sofrimento psíquico e assim evitar novas intervenções constrangedoras da hierarquia, conforme observou Dejours (1992) em seu estudo sobre telefonistas.

Como exemplo, uma trabalhadora demonstrou frustração por não ter reconhecimento do desempenho no trabalho, enfatizando que por mais que o operador se empenhe, a empresa, representada pelo supervisor, sempre desqualifica seus esforços. Cassitto et 
al. (2004) abordam que a ridicularização e as provocações, especialmente realizadas na presença de colegas constituem-se em um exemplo típico de assédio moral. Para Barreto (2004), "o ambiente de trabalho passa a ser dominado pelo medo do coletivo, que leva todos a fazerem o pacto do silêncio". E, nesse sentido, o assédio é coletivo.

Outras situações de assédio moral causadas por supervisores estavam diretamente relacionadas à sua condição de trabalhador com LER/DORT. A narrativa abaixo é reveladora do tratamento irônico e da humilhação pública impetrada por supervisores a uma trabalhadora doente, queixando-se de dor. Outros estudos também observaram que os supervisores compõem o grupo mais importante de agressores (Maciel et al., 2007; Silva, Oliveira e Souza, 2011).

Eu com dor e eles diziam que eu estava fazendo presepada e aí riam e diziam: 'Vai ficar aí! Você não está sentindo nada! Está querendo ir embora para casa, chegar mais cedo. Era desprezo, assédio e tudo. (Luciana)

Conforme enunciados de trabalhadores, ocorreram vários momentos em que os supervisores não satisfeitos com a pressão exercida para aumentar a produtividade, chegavam a tocar nas operadoras doentes para que atingissem a meta, desconsiderando sua condição de enferma e suas limitações físicas. É notado que, no caso do telemarketing, o assédio moral está imbricado com a gestão do trabalho e se acentua na distinção do trabalhador que não consegue mais seguir o ritmo ditado pela produção. Desta forma, tem-se um caminho institucionalizado para as práticas do assédio moral.

Era um estresse psicológico que ficava, que a gente tinha que atingir umas metas de venda de campanha. Eles tocam nas costas. Isso me irritava porque eu já estava com as costas doendo e ela [supervisora] vinha na hora e dizia olá, em! Olá! Vendas! (Luiza)

Laborare. Ano I, Número 1, Julho/2018, pp. 63-84. ISSN 0000-0000. http://trabalhodigno.org/laborare 
A narrativa que segue mostra situações constrangedoras de assédio organizacional para com os trabalhadores doentes quando recebem alta do INSS e retornam ao call center. Ressaltaram que suas cargas de trabalho foram aumentadas, ocasionando piora nas dores.

Quando eu voltei para empresa foi pior ainda. Primeiro porque a empresa me colocou para trabalhar seis horas, mas eu atendia mais ligações. Eu não tinha pausa. Então, chegou um ponto que eu não consegui digitar. Nessa primeira semana de retorno, eu não conseguia digitar. Mesmo assim, chegavam perto, batiam no meu ombro e diziam: Joana, seu tempo! Seu tempo [tempo médio de atendimento] está alto, Joana. (Joana)

Mais uma vez, a forma de gestão nas centrais de teleatendimento é reportada com métodos de "punição ou castigo" por terem ficado doentes e por terem necessitado de afastamentos do trabalho. $\mathrm{O}$ assédio moral tornou-se uma verdadeira estratégia de gerenciamento, pautada na manipulação deliberada da ameaça e da chantagem para desestabilizar as pessoas (Maciel et al., 2007).

O isolamento dos colegas e a humilhação pública são estratégias aplicadas quando o trabalhador obtém alta do INSS e retorna ao trabalho. Essa condição resulta no sentimento de inutilidade que se caracteriza também como forma de punição da empresa, um método de gestão. O operador revela esta situação vivenciada no trecho seguinte.

Como eu não participei do treinamento, automaticamente eu vou chegar lá, eu estou sem senha de sistema, eu vou chegar lá, eles vão me logar [termo utilizado pelos teleoperadores, adaptado de "login" que significa iniciar uma sessão de conexão, em que é feita a identificação do usuário (trabalhador), no sistema operacional] ou então assinar minha folha e eles vão mandar eu aguardar. Enquanto isso fico lá zanzando, andando pela empresa até cumprir minhas horas de trabalho. Eu me sinto inútil. (Márcio)

Laborare. Ano I, Número 1, Julho/2018, pp. 63-84. ISSN 0000-0000. http://trabalhodigno.org/laborare 


\section{Adryanna Cardim de Almeida / Paulo Gilvanne Lopes Pena / \\ Maria do Carmo Soares de Freitas / Mônica Angelim Gomes de Lima}

De acordo com Barreto (2004), a humilhação repetida e de longa duração interfere na vida do sujeito comprometendo sua dignidade e relações afetivas e sociais, deteriorando sua identidade, como retrata Goffman (1988). A autora traz ainda a humilhação como:

Um sentimento de ser ofendido, menosprezado, rebaixado, inferiorizado, submetido, vexado, constrangido e ultrajado pelo outro. É sentir-se um ninguém, sem valor, inútil. Magoado, revoltado, perturbado, mortificado, traído, envergonhado, indignado e com raiva ${ }^{5}$.

A humilhação causa desgosto, amargura e sofrimento. Essa situação ainda diminui a autoestima do trabalhador, porquanto torna pública sua condição, demonstrando a impotência diante dos acontecimentos. A figura de alguns supervisores de call center em muito se assemelha aos "leões de chácara" ou como retrata Heloani (2004), "guardiões das organizações". Esses indivíduos, encorajados pelas práticas organizacionais perversas, que também são trabalhadores, em muitas situações não se dão conta desta sua condição e constantemente desconsideram o outro, realizando práticas de abusos e humilhações.

Todos os informantes deste estudo relataram várias situações de humilhações e abusos cometidas pelos superiores hierárquicos. A supervisão amedronta essas pessoas, onde muitos narram com profunda emoção esses fatos. Isto demonstra que o assédio, nesta categoria, tem relação estrita com o tipo de organização e gestão no trabalho. Di Martino et al. (2003) encontraram resultados similares em outras categorias estudadas, sobre situações constrangedoras no trabalho e assédio moral causadas pelos supervisores.

${ }_{5}^{5}$ Disponível em: $\langle\underline{w w w . a s s e d i o m o r a l . o r g, ~ 2004 〉 . ~}$

Laborare. Ano I, Número 1, Julho/2018, pp. 63-84. ISSN 0000-0000. http://trabalhodigno.org/laborare 
Os consumidores dos serviços ou clientes, quando possuem queixas da empresa, identificam o operador de teleatendimento como responsável, e contra ele expressam suas frustrações e dilemas resultantes das suas aquisições comerciais não cumpridas. Comumente essas expressões tornam-se agressões verbais de natureza moral, incluindo agressões racistas quando há identificação da naturalidade do operador por meio de suas características de linguagem. Assim, clientes podem constituir-se como um grupo de agressores nessa forma de organização do atendimento.

Conforme verificado nos ambientes de trabalho e nos documentos referentes a treinamento de teleoperadores, é salutar que estes trabalhadores percebam as "variações psicológicas e dispensem atenção devida aos clientes", independente do seu comportamento. Para a empresa, os operadores devem saber lidar com todo tipo de cliente para manter a sua "boa imagem". A empresa classifica o cliente como normal, agressivo, meticuloso, sabe tudo, ocupado, pão duro, calado, falante, indeciso e formal. Nas empresas estudadas, não é permitido ao operador desligar a chamada sem antes solicitar várias vezes ao cliente agressor que mude de comportamento.

De acordo o Anexo II da Norma Regulamentadora $\mathrm{n}^{\circ}$ 17, o call center deve garantir pausas no trabalho imediatamente após operação onde tenha ocorrido ameaças, abuso verbal, agressões ou que tenha sido especialmente desgastante, que permitam ao operador recuperar-se e socializar conflitos e dificuldades com colegas, supervisores ou profissionais de saúde ocupacional, especialmente capacitados para tal acolhimento (Brasil, 2007).

Trata-se de pausas terapêuticas para permitir a prevenção ou reduzir danos caracterizados como traumas psíquicos. Ao invés deste apoio psicológico, os próprios supervisores, diante dessas situações constrangedoras, muitas vezes com 
discriminação racial, pressionam ainda mais os trabalhadores a continuar na ligação, não lhes permitindo qualquer reação.

Têm outros [clientes] que ligavam agressivamente, falando com a gente. Tem uns supervisores que dizem: vá, você tem obrigação de atender. Você está aqui para isso!. (Andréia)

Teve um [cliente] que falou que ia me botar na justiça, que já tinha entrado na justiça e colocado atendente. Eu, 'Calma senhor'. 'Você está falando da Bahia, não é? Por isso que você está com essa vozinha de merda. (Silvana)

A gestão da empresa também se utiliza desses clientes como mais uma forma de controle dos trabalhadores a fim de aumentar a produtividade. Nessa perspectiva, o cliente ao fazer uso do serviço de telemarketing, vigiará o trabalho do teleoperador, atuando como mais um suporte gerencial para acelerar e controlar a atividade deste trabalhador (Pena, Cardim e Araújo, 2011).

Para Soboll (2007, p.18), “o discurso e a ética economicista acabam justificando tais práticas como necessárias, na tentativa de legitimar e banalizar a violência utilizada como uma política de gestão". Ressalta-se que a utilização de intimidações e aviltamento, mesmo com o objetivo de melhorar a atuação do trabalhador é considerada assédio moral.

\section{IATROGENIA MÉDICA E ASSÉDIO MORAL}

Em todas as entrevistas houve relatos de situações de assédio moral ou violência psicológica causadas por médicos do trabalho das empresas, principalmente aos trabalhadores com LER/DORT. Seguem alguns relatos.

Ele [médico do trabalho da empresa] sempre batendo na tecla de que não ia olhar. E que se ele olhasse, ele ia se comover. Ele chegou ao ponto de dizer isso, 'se eu olhar, eu vou me comover,

Laborare. Ano I, Número 1, Julho/2018, pp. 63-84. ISSN 0000-0000. http://trabalhodigno.org/laborare 
então prefiro nem olhar'. Aí, eu comecei a ficar nervosa e comecei a entrar em crise de choro. Ele pegou o relatório de minha médica e saiu pelo corredor mostrando. Mostrando até para os outros médicos e dando risada. (Teresa)

A trabalhadora refere que o médico usava de profunda ironia, debochando da sua condição de doente, utilizando-se de ataques psicológicos para atentar contra a sua dignidade. Além disso, esse profissional expôs a situação dessa operadora para os seus pares, ridicularizando-a, o que ocasionou instabilidade emocional abalizada pelo choro. Essas atitudes causam danos à autoestima, à identidade ou ao desenvolvimento do indivíduo. Nota-se que esses atos de violência moral foram citados, repetidas vezes, nas entrevistas. Para Barreto (2004), esses atos estão na esfera da "violação dos direitos humanos, uma vez que atingem a identidade do trabalhador e a sua dignidade".

No dia que eu fui levar o pedido de prorrogação ele sentou na sala com outro médico e ficaram querendo que eu voltasse. É melhor você voltar! [fala em tom de ameaça]. E eu fiquei nervosa que até minha lente de contato caiu no chão. Foi horrível mesmo, uma pressão psicológica que eles fizeram comigo. Ele queria que eu assinasse um documento que eu estava apta para trabalhar. Dizendo também, sou médico do INSS e você está vendo que os médicos estão dando alta para as pessoas. (Luiza)

Uma série de atitudes caracterizadas como violência moral é realizada cotidianamente pelos médicos do trabalho de empresas no ambiente de trabalho. Observa-se que a figura desses médicos está sempre associada ao carrasco, a um indivíduo cruel, desumano e algoz. Esses profissionais utilizam conhecimentos técnicos sobre as doenças para exercer mais um mecanismo de controle da organização do trabalho, e não se responsabilizam pelo cuidado com a saúde. Intimidação, insulto, ameaça, coação, entre outros, são exemplos do uso dessas estratégias de temor psicológico em todas as instâncias setoriais e hierárquicas da empresa.

Laborare. Ano I, Número 1, Julho/2018, pp. 63-84. ISSN 0000-0000. http://trabalhodigno.org/laborare 
Se por um lado as práticas de assédio moral têm se tornado constantes nos call centers, também abusos e humilhações idênticas dirigidas a tais trabalhadores causam perplexidade quando ocorrem em locais onde procuram amparo, como nos postos do Instituto Nacional da Seguridade Social - INSS e na Superintendência Regional do Trabalho e Emprego (SRTE). Ressalta-se que essas experiências podem trazer danos irreparáveis à saúde mental e física desses indivíduos.

Os procedimentos médicos de assédio, aqui listados, não condizem com as atribuições deste profissional. Trata-se de uma perversão da prática médica que viola princípios éticos, ainda que ocorra com certa frequência na prática da medicina do trabalho. Todavia, encontra-se absolutamente integrada ao modelo taylorista de gestão (Pena, Cardim e Araújo, 2011). Isso significa que transformaram a prática de cura e conforto do paciente em procedimento de sofrimento e agravamento do prognóstico, agregando os distúrbios psíquicos às LER/DORT em função da violência psicológica empreendida no consultório.

Trata-se, portanto, de uma prática médica iatrogênica. A iatrogênese é um termo comumente utilizado para apontar um maleficio ou um dano decorrente a um ato médico qualquer. Illitch (1975) o utiliza com um sentido mais ampliado para designar também os efeitos não desejados provocados sobre a saúde, não apenas por seu impacto direto, mas igualmente pelas transformações que ocasiona em âmbito social e simbólico, da rotina negligente, da negligência criminosa. Para Illitch (1975), a “invasão da medicina não reconhece limites". 


\section{ASSÉDIO MORAL INSTITUCIONALIZADO: "AQUI ERA PARA EU ME SENTIR PROTEGIDO"}

A narrativa abaixo de um operador de telemarketing com LER/DORT com musculatura desenvolvida, típica de quem praticava exercícios físicos, constituiu-se num exemplo de violência psicológica causada por um auditor fiscal do trabalho da SRTE (nomenclatura atual para a Delegacia Regional do Trabalho - DRT).

Este trabalhador foi prestar uma queixa neste órgão, ao se dirigir a este fiscal, foi acusado de utilizar-se de artifícios para não trabalhar. Ao ouvir esta acusação, este relatou o drama do constrangimento resultante, que o desequilibrou emocionalmente, deixando-o desnorteado ao ponto de esquecer seu horário para realização do tratamento fisioterapêutico. Observa-se claramente a situação de violência, visto o constrangimento causado e a insinuação ofensiva e maliciosa que desestabilizaram esse indivíduo, bem como atingiu a sua dignidade.

Essa semana eu fui a DRT e o fiscal do trabalho, eu fui conversar com ele e ele simplesmente disse que eu teria que estar procurando outra coisa para fazer que aquilo não era emprego para eu estar trabalhando não. Que eu era um cara forte e com um porte forte desse, que eu poderia estar usando outro artifício para não trabalhar. Mas ele, com outras palavras, ele disse que eu estava usando um artifício para não trabalhar. Aí eu me senti muito mal naquela hora ali. Mas deixei para lá, fui para casa. Eu tinha até fisioterapia para fazer... saí e fui para casa direto. (Márcio)

No âmbito da Previdência Social, os operadores de telemarketing com LER/DORT trazem, frequentemente, em suas narrativas, expressões como "descaso", "destrato", "desfaz", quando se referem ao tratamento fornecido por médicos peritos do INSS. Para eles, a violência moral e psicológica cometida por estes, vem em primeiro plano, o que é inaceitável. Já o benefício previdenciário perdido é percebido em suas falas como

Laborare. Ano I, Número 1, Julho/2018, pp. 63-84. ISSN 0000-0000. http://trabalhodigno.org/laborare 


\section{Adryanna Cardim de Almeida / Paulo Gilvanne Lopes Pena / \\ Maria do Carmo Soares de Freitas / Mônica Angelim Gomes de Lima}

segundo plano, porque esses trabalhadores, inúmeras vezes, explicitam que "podem até perder o benefício, mas não desfazer do que estão sentindo”. Essas pessoas são acusadas e impossibilitadas de se defenderem, visto estarem fragilizadas pela doença, assim como, com sua condição de doente sendo atestada por esses profissionais. A médica perita "chega a querer que a trabalhadora não se cuide", sugerindo inclusive a retirada do aparelho odontológico, já que "dá trabalho para ser escovado".

E o próprio INSS, porque o perito do INSS, o quê que é aquilo? Ele te desfaz o tempo inteiro. Que não vê motivo, que não vê incapacidade, manda você fazer exercício que você não tem condições de fazer. É complicado porque eles não aceitam. Além de não aceitar, eles não entendem que você tem esse problema. Tudo bem, eles podem até não conceder benefício, mas aí desfazer do que você está sentindo? É complicado. Mas aí a destratar ou simplesmente ignorar? Eu vou para perícia com o relatório, vou com o exame, vou com remédio, receita médica, com tudo, e mesmo assim ele destrata você, faz um monte de perguntas, o que é que você está fazendo da sua vida. Teve um que virou para mim agora e falou: por que você não entra na faculdade? (Joana)

Mesmo com as diferenças conceituais em torno da terminologia "assédio moral", não há divergências entre os autores sobre as consequências provocadas pela exposição ao assédio moral e à violência psicológica aos trabalhadores. Os efeitos dessas exposições à saúde são diversos e, muitas vezes, dependem da duração e intensidade dos estímulos estressantes. Essas situações de violência causam ou contribuem para inúmeros transtornos psicopatológicos, psicossomáticos e comportamentais.

Dentre os transtornos psicopatológicos, os mais citados na literatura são: depressão, ansiedade, melancolia, insônia, apatia, reações de medo, alterações de humor, insegurança, entre outros. Entre as desordens psicossomáticas estão a sudorese, tremores, taquicardia, dor e úlceras estomacais, perda de peso, dermatites, entre outros. O isolamento social, reações auto-agressivas, disfunção sexual, transtornos 
alimentares e aumento no consumo de álcool, drogas e cigarros figuram como os sintomas comportamentais mais comuns (Di Martino et al., 2003; Cassitto et al., 2004; Maciel et al., 2007).

As empresas, por meio dos seus serviços médicos, e as instituições negam o nexo causal da patologia dessa operadora com o trabalho. A narrativa expressa a transformação da operadora doente e estigmatizada em portadora das evidências de sua enfermidade para contrapor-se a essa negação. As consequências geradas por esses atos de violência da empresa e de médicos peritos do INSS resultam na sua autoestima abalada.

Estudos demonstraram que um elevado percentual de indivíduos vítimas de violência moral procurou tratamento psiquiátrico e que 1 (uma) entre 5 (cinco) pessoas relatou estar em uso de medicamentos como consequência dessas experiências (Agência Europeia para a Segurança e a Saúde no Trabalho, 2002). Outra trabalhadora relata que após ter sido submetida às humilhações por médicos da empresa, ficou tão desestruturada que foi pedir ajuda ao sindicato da categoria, uma vez que tinha medo de adentrar as dependências do serviço médico da empresa.

As estórias desses operadores de telemarketing com LER/DORT foram marcadas por experiências de sofrimento vivenciadas tanto no ambiente de trabalho quanto em locais considerados em sua essência, como de suporte ao trabalhador, nos quais as injustiças, humilhações, abusos, constrangimentos, maus-tratos e coações os atingiram psicologicamente.

Laborare. Ano I, Número 1, Julho/2018, pp. 63-84. ISSN 0000-0000. http://trabalhodigno.org/laborare 


\section{CONCLUSÃO}

$\mathrm{O}$ processo de trabalho do telemarketing tem apresentado uma singularidade característica enquanto constituinte da gestão da força de trabalho e gestão da produção que é a presença do assédio moral. Assim sendo, o trabalhador é atingido mesmo antes de expressar no corpo a sua dor. Provavelmente, a dor, no corpo desse trabalhador, o impulsiona ao decidir pela busca do cuidado, decidir interagir com o sistema de saúde e previdenciário para confirmar a condição de "doença” e fazer jus ao afastamento dessa condição de trabalho tão degradante. As imagens dos exames complementares apenas produzem "visibilidade" à doença "LER/DORT", dando primeiro plano ao acometimento físico, passível de legitimação pelos sistemas (de saúde, previdenciário e do trabalho).

Este estudo contribuiu para descrever fenômenos de assédio moral em empresas de telemarketing da cidade de Salvador-BA, em consonância com o apresentado em outros estudos. Há um sistema de assédio na sociedade: empresa, cliente, prática médica e instituições. $\mathrm{O}$ assédio pode responder por grande parte de seu sofrimento e, por isso, torna-se difícil a ação protetora do estado na atualidade. Importante salientar para a continuidade de estudos que explorem mais as relações com os colegas de trabalho, a construção de resistências, a percepção da injustiça e outras significações deste objeto de estudo e que, por se tratar de um estudo de natureza qualitativa, faz-se necessário manter cuidado com possíveis generalizações. 


\section{REFERÊNCIAS BIBLIOGRÁFICAS}

Agência Europeia para a Segurança e a Saúde no Trabalho. (2002). O assédio moral no local de trabalho. ISSN 1681-2166. Disponível em: http://agency.osha.eu.int. Acesso em: 17 out. 2015.

Barreto M. (2004). O que é assédio moral? Disponível em: http:// http://www.assediomoral.org/spip.php?article1. Acesso em: 18 out. 2015.

Barthes R. (1997). Elementos de semiologia. 10. ed. São Paulo: Cultrix; 1997. 116p.

Beswick J, Gore J, Palferman D. (2006). Bullying at work: A review of the literature. Health and Safety Laboratory. Working Paper Series. Vol. 6. N. 4.

Braga R. (2006). Infotaylorismo: o trabalho do teleoperador e a degradação da relação de serviço. Revista de Economia Política de las Tecnologias de la Información y Comunicación. Vol. VIII. N. 1.

Brasil. Norma Regulamentadora n. 17- Anexo II, de 30 de março de 2007. Dispõe sobre trabalho em atendimento/telemarketing. Diário Oficial da República Federativa do Brasil. Brasília; 2007. Disponível em: http://www.mte.gov.br/seg_sau/leg_normas_regulamentadoras. Acesso em: 10 ago. 2008 .

Cassitto MG, Fattorini E, Gilioli R, Rengo C. (2004). Sensibilizando sobre el acoso psicológico en el trabajo. Serie protección de la Salud de los Trabajadores. Organización Mundial de la Salud. N. 4. Disponible en: http://www.who.int/occupational_health/publications/en/pwh4sp.pdf.

Acesso em: 10 ago. 2008.

Dejours C. (1992). A loucura do trabalho: estudo de psicopatologia do trabalho. $5^{\text {a }}$ edição ampliada. São Paulo: Cortez, Oboré.

Di Martino V, Hoel H, Cooper CL. (2003). Preventing violence and harassment in the workplace. European Foundation for the Improvement of Living and Working Conditions. Available to: http://www.eurofound.europa.eu/pubdocs/2002/109/en/1/ef02109en.pdf. Acesso em: 13 ago 2008.

Fernandes SRP. (2002). Organização e condições de trabalho em telemarketing: repercussões na saúde psíquica dos trabalhadores. In: Jacques M, Godo W, org. Saúde Mental \& Trabalhos-leitura. Petrópolis: Vozes. p.247-70.

Goffman E. (1988). Estigma: notas sobre a manipulação da identidade deteriorada. Rio de Janeiro: LTC. p.12-50. 
Geertz C. (1989). Uma Descrição Densa: Por uma Teoria Interpretativa da Cultura. In: Geertz C. A Interpretação das Culturas. Rio de Janeiro: Guanabara. p.3-7.

Guimarães, LAM; Rimoli, AO. (2006). "Mobbing" (assédio psicológico) no trabalho: uma síndrome psicossocial multidimensional. Psic.: Teor. e Pesq. Vol. 22, N. 2. pp. 183-192.

Heloani JR. (2004). Assédio Moral: um ensaio sobre a expropriação da dignidade no trabalho. RAE - Revista de Administração de Empresas. Vol. 3, N. 1.

ILLICH, Ivan. (1975). A expropriação da saúde: nêmesis da medicina. 3. ed. Rio de Janeiro: Nova Fronteira. 164p.

Lucca SR, Campos CR. (2010). Saúde mental e trabalho: uma discussão a partir do estudo de trabalhadores da atividade de teleatendimento. Revista Bras. Med. Trab. Vol. 8, N. 1.

Maciel RH, Cavalcante R, Matos TGR, Rodrigues S. (2007). Auto relato de situações constrangedoras no trabalho e assédio moral nos bancários: uma fotografia. Psicol. Soc. Vol. 19, N. 2. p. 117-128.

Norman K, Tornqvist EW, Toomingas A. (2008). Working Conditions in a Selected Sample of Call Centre Companies in Sweden. International Journal of Occupational Safety and Ergonomics. Vol. 14, N. 2. p.177-194.

Organización Internacional del Trabajo. (1998). Violencia en el lugar de trabajo: un nuevo problema mundial. Trabajo, Revista de la OIT. N. 26, sept./oct. Disponible en: http:// http://www.ilo.org/global/about-the-ilo/newsroom/news/WCMS_008502/lang-es/index.htm. Acesso em: 30 abr. 2018.

Pena PGL, Cardim A, Araújo MPN. (2011). Taylorismo cibernético e Lesões por Esforços Repetitivos em operadores de telemarketing em Salvador-Bahia. Caderno CRH. V. 24 (número especial 1). p. 133-153.

Rosenfield CL. (2007). Paradoxos do capitalismo e trabalho em call centers: Brasil, Portugal e Cabo Verde. Caderno CRH. Vol. 20, N. 51. p. 447-462.

Silva EF, Oliveira KKM, Souza PCZ. (2011). Saúde mental do trabalhador: o assédio moral praticado contra trabalhadores com LER/DORT. Rev. bras. Saúde Ocup. Vol. 36, N. 123 . p. $56-70$.

Soboll LA. (2007). Assédio Moral no Brasil: questões conceituais. I Simpósio Brasileiro De Saúde do Trabalhador. Associação Brasileira de Pós-Graduação em Saúde Coletiva - ABRASCO.

Thirión JM. (2007). Los Call Centers y Los Nuevos Trabajos del Siglo XXI. Confines, Nuevo León. Vol. 3, N. 5. p. 49-57.

Laborare. Ano I, Número 1, Julho/2018, pp. 63-84. ISSN 0000-0000. http://trabalhodigno.org/laborare 
Vieira, Carlos Eduardo Carrusca, Lima, Francisco de Paula Antunes, \& Lima, Maria Elizabeth Antunes. (2012). E se o assédio não fosse moral? perspectivas de análise de conflitos interpessoais em situações de trabalho. Revista Brasileira de Saúde Ocupacional. Vol. 37, N. 126. p. 256-268. Disponível em: https://dx.doi.org/10.1590/S0303-765720120002000071. Acesso em: 10 ago. 2016.

Ziliotto DM; Oliveira BO. (2014). A Organização do Trabalho em Call Centers: Implicações na Saúde Mental dos Operadores. Rev. Psicol., Organ. Trab. Vol. 14, N. 2. p. 169-179. 